\title{
In vitro combined effect of oregano essential oil and caprylic acid against Salmonella serovars, Escherichia coli 0157:H7, Staphylococcus aureus and Listeria monocytogenes
}

\author{
Radka Hulánková, Gabriela Bořilová \\ Department of Meat Hygiene and Technology, Faculty of Veterinary Hygiene and Ecology, \\ University of Veterinary and Pharmaceutical Sciences Brno, Czech Republic
}

Received August 29, 2011

Accepted December 14, 2011

\begin{abstract}
In vitro inhibition of foodborne pathogens via action of natural antimicrobials - caprylic acid (CA) and essential oil from Origanum vulgare L. (OEO) with high carvacrol content (72\%) was evaluated. For 15 Salmonella strains the minimum inhibitory concentration (MIC) determined by broth microdilution method ranged between $3.67-4.33 \mu \mathrm{l} \cdot \mathrm{ml}^{-1}$ for CA and between $0.48-0.57$ $\mu \mathrm{l} \cdot \mathrm{ml}^{-1}$ for OEO. For 7 Listeria monocytogenes strains the MIC ranged between $2.17-2.83 \mu 1 \cdot \mathrm{ml}^{-1}$ for CA and between $0.52-0.58 \mu \mathrm{l} \cdot \mathrm{ml}^{-1}$ for OEO. Type strains of Escherichia coli $\mathrm{O} 157: \mathrm{H} 7$ and Staphylococcus aureus were tested, too, with MIC of CA $3.60 \mu 1 \cdot \mathrm{ml}^{-1}$ and $3.20 \mu \mathrm{l} \cdot \mathrm{ml}^{-1}$ and MIC of OEO $0.51 \mu \mathrm{l} \cdot \mathrm{ml}^{-1}$ and $0.48 \mu \mathrm{l} \cdot \mathrm{ml}^{-1}$, respectively. Furthermore, it was found that the MIC of CA can be decreased by even low addition $(0.05 \%)$ of citric or acetic acid and to a lesser extent by lactic acid, whereas the MICs of OEO did not notably decrease. Combined application of CA and OEO determined by FIC index led only to an additive effect $(0.5 \leq \mathrm{FIC} \leq 1)$. Combination of natural additives OEO, CA and eventually acetic or citric acid seems to have the potential to be an effective mixture for inhibition of foodborne pathogens, predominantly Salmonella spp. and L. monocytogenes, even in only slightly acidic food.
\end{abstract}

MIC, FIC, natural antimicrobials, Origanum vulgare, octanoic acid, foodborne pathogens

In recent years many researchers have focused on natural antimicrobials as an alternative to synthetic food additives, which are not regarded well by consumers. Several studies have proven the essential oil from Origanum vulgare L. to be very effective or even the most effective essential oil tested for inhibition of gram-negative bacteria such as salmonellae (Friedman et al. 2002; Nevas et al. 2004; Penalver et al. 2005), which are generally regarded as less sensitive to essential oils. Membrane disintegration seems to be the primary inactivation mechanism of oregano and thyme essential oils (Burt 2004).

Caprylic acid is a saturated medium-chain fatty acid $\left(\mathrm{C}_{8}\right)$ with antibacterial and antifungal activity found naturally in coconut oil, bovine and human milk (Jensen et al. 1990). It has been suggested that the antimicrobial activity of medium-chain fatty acids is targeted on cell membrane, leading to disruption of electron transport chain and disruption of oxidative phosphorylation (Desbois and Smith 2010). In a study with $\mathrm{C}_{2}-\mathrm{C}_{18}$ fatty acids caprylic acid was the most effective against Salmonella serovars and E. coli (Skřivanová et al. 2006).

The application of both essential oils and fatty acids such as caprylic acid in food preservation is limited since generally greater concentrations of these highly aromatic compounds are required to achieve the same effect in food matrix as in vitro (Gutierrez et al. 2009; Desbois and Smith 2010). Finding effective combinations of antimicrobials could enable to lower the concentrations of the individual substances to sensory acceptable level.

To our knowledge, the effect of the combined application of medium-chain fatty acids and phenolic compounds against foodborne pathogens has not yet been reported. The aim

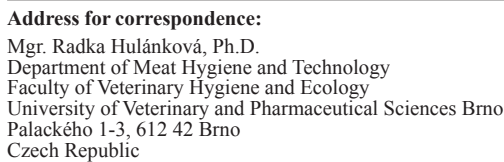

Phone: +420541562750

Fax: +420541321230

E-mail: hulankovar@vfu.cz

http://www.vfu.cz/acta-vet/actavet.htm 
of this study was to evaluate the combined effect of oregano essential oil and caprylic acid and their mixture with other organic acids on inhibition of four foodborne pathogens, Salmonella enterica, Escherichia coli O157:H7, Staphylococcus aureus and Listeria monocytogenes.

\section{Materials and Methods}

Oregano essential oil and organic acids

The oregano essential oil (OEO) from Origanum vulgare L. originating from Spain was purchased from Nobilis Tilia (Czech Republic). The major components determined by gas chromatography-mass spectrometry (as reported by producer) were carvacrol (72\%), p-cymen (7.6\%) and $\gamma$-terpinen $(5.7 \%)$. Other chemicals used were caprylic acid (CA, $\geq 98 \%$, Sigma-Aldrich, USA) and L-lactic acid (80\%, purum), acetic acid (99.8\%, p.a.) and citric acid (anhydrous, p.a.) purchased from Lach-Ner, Czech Republic.

Stock solutions (48\%) of oregano essential oil and caprylic acid were prepared in ethanol and further diluted with Tryptic Soy Broth (TSB, Oxoid, UK). The other acids were diluted in distilled water to form $10 \%$ solutions $(\mathrm{w} / \mathrm{v})$ and further diluted with TSB.

\section{Bacterial strains}

The bacteria used in this study were Salmonella enteritidis ATCC 13076, Escherichia coli O157:H7 ATCC 700728, Staphylococcus aureus ATCC 25923, Listeria monocytogenes ATCC 13932 and six Listeria monocytogenes strains $1 / 2 \mathrm{a}, 1 / 2 \mathrm{~b}$ and $1 / 2 \mathrm{c}$ isolated from minced meat, heat-treated and non-heattreated meat products. Fourteen Salmonella strains including Enteritidis PT1b, PT4, PT4b, PT8, PT13, PT21, Typhimurium DT104 and DT120 and serotype Montevideo isolated from meat, meat products and environmental swabs from meat processing plants were kindly provided by National Public Health Institute, Czech Republic. All strains were kept frozen at $-80{ }^{\circ} \mathrm{C}$ in TSB with $20 \%$ glycerol. Before using the cultures were twice sub-cultivated in TSB at $37^{\circ} \mathrm{C}$ for $24 \mathrm{~h}$ and then diluted in TSB to approximately $3 \times 10^{6}$ cells $\cdot \mathrm{ml}^{-1}$ using the McFarland turbidity scale.

Determination of the minimum inhibitory concentration (MIC)

The minimum inhibitory concentrations (MIC) of OEO and CA were determined using 96-well microtitre plates (Gamma group, Czech Republic). Each well contained $100 \mu \mathrm{l}$ of the OEO solution (final concentration $0.1-1 \mu \mathrm{l} \cdot \mathrm{ml}^{-1}$ ) or CA solution (final concentration 1-10 $\mu \mathrm{l} \cdot \mathrm{ml}^{-1}$ ) and $50 \mu \mathrm{l}$ of bacterial suspension. Negative controls and positive controls in TSB with ethanol were included. The plates were incubated at $37^{\circ} \mathrm{C}$ for $24 \mathrm{~h}$ and the MIC was determined as the lowest concentration required to prevent visible growth. Experiments were performed in duplicate and replicated $3 \times$

Determining the effect of organic acids on MICs

The effect of organic acids on microbial inhibition by OEO and CA was determined by the same method. Each well contained $50 \mu \mathrm{l}$ of OEO or CA solution (final concentrations as previously mentioned), $50 \mu \mathrm{l}$ of lactic, acetic or citric acid (final concentration $0.05 \%$ ) and $50 \mu \mathrm{l}$ of bacterial suspension. Experiments were performed in duplicate and replicated $3 \times$.

\section{Checkerboard method}

The checkerboard method was performed using 96-well microtitre plates to obtain the fractional inhibitory concentration (FIC) index. Each well contained $50 \mu \mathrm{l}$ of OEO solution (final concentration $0.0125-0.6 \mu 1 \cdot \mathrm{ml}^{-1}$ ), $50 \mu \mathrm{l}$ of CA solution (final concentration $0.125-6 \mu \mathrm{l} \cdot \mathrm{ml}^{-1}$ ) and $50 \mu \mathrm{l}$ of bacterial suspension. Negative and positive controls were included and the plates were incubated at $37^{\circ} \mathrm{C}$ for $24 \mathrm{~h}$. The FIC indices were calculated according to Gutierrez et al. (2009) as $\mathrm{FIC}_{\mathrm{OEO}}+\mathrm{FIC}_{\mathrm{CA}}$, where $\mathrm{FIC}_{\mathrm{OEO}}=\mathrm{MIC}_{\mathrm{OEO}}$ in combination $/ \mathrm{MIC}_{\mathrm{OEO}}$ alone and $\mathrm{FIC}_{\mathrm{CA}}=$ $\mathrm{MIC}_{\mathrm{CA}}$ in combination/MIC $\mathrm{CA}_{\mathrm{A}}$ alone. The results were interpreted as synergy $(\mathrm{FIC}<0.5)$, addition $(0.5 \leq \mathrm{FIC} \leq 1)$, indifference $(1<\mathrm{FIC} \leq 2)$ or antagonism $(\mathrm{FIC}>2)$. Experiments were performed in triplicate.

\section{Statistical evaluation}

Kruskal-Wallis ANOVA was performed by StatPlus 2008 Professional v. 5.2.5.0 software. A level of $P<0.05$ was considered significant. FIC indices were not subjected to analysis since not enough data were obtained for statistical evaluation.

\section{Results}

\section{The MICs of OEO and CA}

Minimum inhibitory concentrations of CAagainst Salmonella and Listeria monocytogenes wild types ranged between $3.67-4.33 \mu 1 \cdot \mathrm{ml}^{-1}$ and $2.17-2.83 \mu 1 \cdot \mathrm{ml}^{-1}$, respectively, whereas the MICs of OEO ranged between $0.48-0.57 \mu \mathrm{l} \cdot \mathrm{ml}^{-1}$ and $0.55-0.58 \mu \mathrm{l} \cdot \mathrm{ml}^{-1}$, respectively. The MICs of type strains are listed in Table 1. No significant difference was observed in MIC of CA and OEO among Salmonella serovars and the same held true for Listeria 
Table 1. Sensitivity of bacterial type strains to caprylic acid, oregano essential oil and their combination

\begin{tabular}{lcccc}
\hline Strain & Type strain number & $\begin{array}{c}\text { MIC of CA }\left(\mu 1 \cdot \mathrm{ml}^{-1}\right) \\
(\text { mean } \pm \text { SD })\end{array}$ & $\begin{array}{c}\text { MIC of OEO }\left(\mu 1 \cdot \mathrm{ml}^{-1}\right) \\
(\mathrm{mean} \pm \mathrm{SD})\end{array}$ & $\begin{array}{c}\text { FIC } \\
(\mathrm{mean} \pm \mathrm{SD})\end{array}$ \\
\hline Salmonella Enteritidis & ATCC 13076 & $4.33 \pm 0.52^{\mathrm{a}}$ & $0.50 \pm 0.09$ & $0.84 \pm 0.00$ \\
Escherichia coli O157:H7 & ATCC 700728 & $3.60 \pm 0.52^{\mathrm{ab}}$ & $0.51 \pm 0.09$ & $0.94 \pm 0.11$ \\
Staphylococcus aureus & ATCC 25923 & $3.20 \pm 0.75^{\mathrm{b}}$ & $0.48 \pm 0.08$ & $0.91 \pm 0.00$ \\
Listeria monocytogenes & ATCC 13932 & $2.36 \pm 0.67^{\mathrm{c}}$ & $0.52 \pm 0.08$ & $0.82 \pm 0.18$ \\
\hline
\end{tabular}

MIC - minimum inhibitory concentration, FIC - fractional inhibitory concentration, CA - caprylic acid, OEO oregano essential oil, a,b,c - significant difference $(P<0.05)$

monocytogenes strains. L. monocytogenes strains were the most sensitive against CA with average MIC of only $2.36 \pm 0.22 \mu \mathrm{l} \cdot \mathrm{ml}^{-1}$, followed by $S$. aureus and E. coli, while the salmonellae were the most resistant $\left(4.22 \pm 0.18 \mu \mathrm{l} \cdot \mathrm{ml}^{-1}\right)$. There was no significant difference in MICs of OEO among type strains; however, Listeria monocytogenes strains seemed to be the most resistant with average MIC of $0.56 \pm 0.02 \mu \mathrm{l} \cdot \mathrm{ml}^{-1}$.

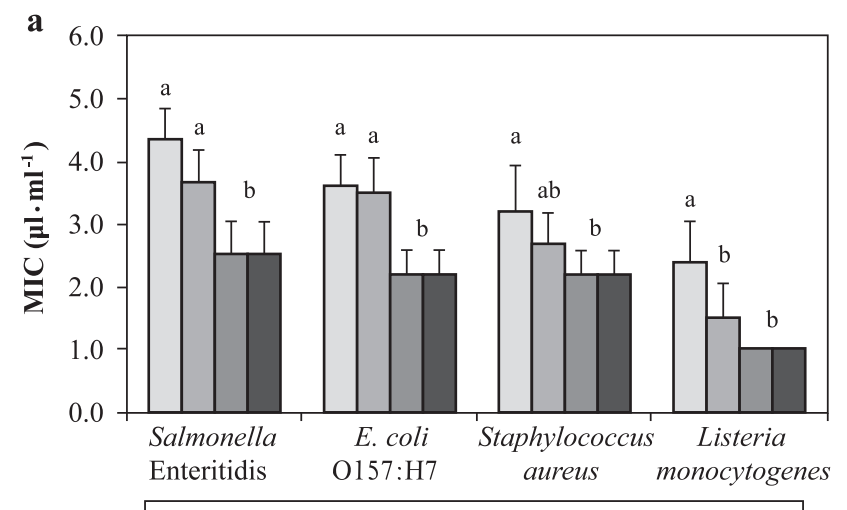

$\square$ Control $\square$ Lactic acid $\square$ Acetic acid $\square$ Citric acid

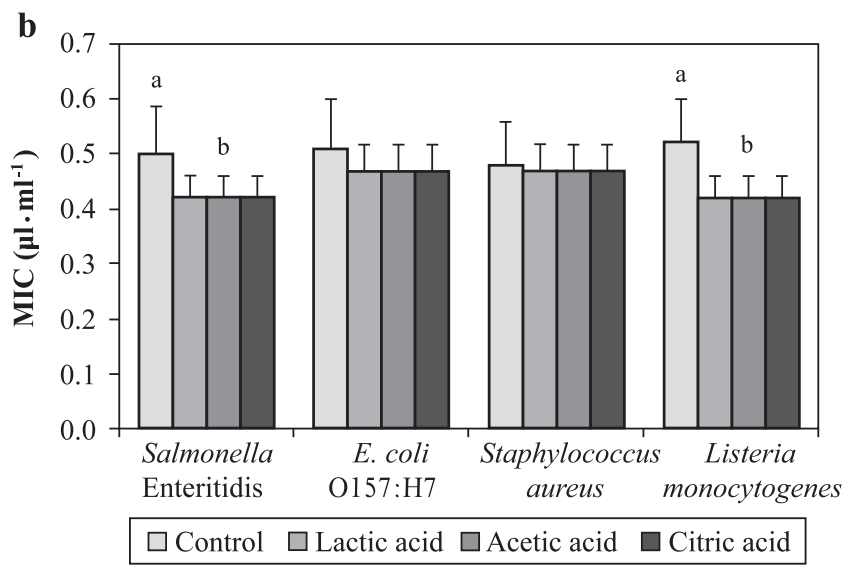

Fig. 1. Effect of acids $(0.05 \% \mathrm{w} / \mathrm{v})$ on minimum inhibitory concentration (MIC) of caprylic acid (a) and oregano essential oil (b) for bacterial type strains with statistical differences between controls and acids marked 
The effect of organic acids on MICs of OEO and CA

The effect of organic acids was tested only on bacterial type strains. In presence of shortchain organic acids (lactic, acetic and citric), the MICs of CA were lowered considerably (Fig. 1a), especially of Listeria monocytogenes and to a lesser extent of Salmonella Enteritidis. The effect of acetic and citric acid on MICs of CA was much more pronounced in comparison with lactic acid. The MICs of OEO were less affected (Fig. 1b) as only MICs of OEO against L. monocytogenes $(P=0.018)$ and Salmonella Enteritidis $(P=0.043)$ were lowered significantly in presence of organic acids.

The combined effect of OEO and CA

Combined effects of the antimicrobials in question were evaluated by means of FIC indices listed in Table 1. The FIC indices for type strains varied between 0.82 and 0.94 . These values (between 0.5 and 1.0) can be interpreted as an additive effect.

\section{Discussion}

Despite no significant differences in MIC OEO between bacterial type strains, the strains of $L$. monocytogenes seemed to be the most resistant followed by Salmonella enterica strains. Together with $S$. aureus type strain being the most sensitive, no general conclusions about different resistance of gram-positive and gram-negative bacteria can be made in our case. Higher sensitivity of gram-positive bacteria (e.g. L. monocytogenes, S. aureus) compared to gram-negative bacteria ( $S$. Typhimurium, nonpathogenic $E$. coli) to OEO was reported by Nevas et al. (2004). However, in a study of Di Pasqua et al. (2005), the MIC increased as followed: $S$. Typhimurium, E. coli $\mathrm{O} 157: \mathrm{H7}$, L. monocytogenes and $S$. aureus, suggesting the opposite. Friedman et al. (2002) observed similar sensitivity of E. coli O157:H7 and Salmonella Hadar strains to OEO, whereas L. monocytogenes was more resistant.

The choice of strains can play an important role in these comparisons since the MICs often vary considerably between strains. Although no major differences were noted in our case, in a study of Penalver et al. (2005) the MIC of OEO ranged from $2.5 \mu \mathrm{l} \cdot \mathrm{ml}^{-1}$ for Salmonella Enteritidis up to $10 \mu \mathrm{l} \cdot \mathrm{ml}^{-1}$ for serovars Typhimurium and Essen. The same results were obtained for caprylic acid. No major differences among various Salmonella and L. monocytogenes strains were found in this study, although e.g. Boyen et al. (2008) measured different MICs of CA against 54 porcine Salmonella Typhimurium strains. In our study, greater sensitivity of gram-positive bacteria to caprylic acid compared to gram-negative bacteria was observed. L. monocytogenes was the most sensitive followed by $S$. aureus, E. coli O157:H7 and Salmonella Enteritidis. Similarly, Nobmann et al. (2009) observed greater sensitivity of L. monocytogenes (MIC $5 \mathrm{mM}$ ) followed by E. coli O157:H7 (MIC $10 \mathrm{mM}$ ) and Salmonella Typhimurium (MIC > $20 \mathrm{mM}$ ).

Simultaneous application of CA and OEO tested on bacterial type strains led to an additive effect, with FIC ranging between 0.82 and 0.94 (Tab. 1). The lowest FIC index was noted for L. monocytogenes and Salmonella Enteritidis. Although no synergy was detected between $\mathrm{OEO}$ and $\mathrm{CA}$, the additive effect still enables to obtain the same antimicrobial effect as that of OEO or CA alone using lower concentrations of both of the substances simultaneously. The effective concentration can be very important for use in food since both CA and OEO have a distinctive odour and the efficiency of essential oils is generally lowered in foodstuffs such as meat, requiring higher concentrations that are often sensory unacceptable (de Souza et al. 2009; de Oliveira et al. 2010).

As a part of this study we investigated whether the effective concentrations could be further lowered by addition of other organic acids in subinhibitory concentrations. At lower $\mathrm{pH}$ the essential oils are more hydrophobic and can more easily dissolve in lipids of bacterial cell membrane (Juven et al. 1994). Several authors reported synergy or 
additive effect of OEO (or its main component carvacrol) and lactic, acetic or citric acid against foodborne pathogens (Dimitrijevic et al. 2007; Zhou et al. 2007; de Souza et al. 2009; de Oliveira et al. 2010). In our study the presence of lactic, acetic or citric acid at concentration of either $0.05 \%$ (Fig. 1b) or $0.1 \%$ (unpublished data) did not lead to a significant reduction of MIC of OEO with the exception of $L$. monocytogenes $(P=0.018)$ and $S$. Typhimurium $(P=0.043)$. The presence of buffering substances (dipotassium hydrogen phosphate) in the cultivating medium and consequently minimal drop of $\mathrm{pH}$ (6.8 - 7.3; unpublished data) could explain this failure.

The effect of addition of other organic acids on MIC of CA was more pronounced. At low $\mathrm{pH}$, more of the organic acid will be in the undissociated form which can diffuse across the cell membrane (Ricke 2003). The enhanced effectiveness of CA at low pH is well known and has been reported against both Salmonella spp. and Listeria monocytogenes (Kinderlerer and Lund 1992; Boyen et al. 2008). L. monocytogenes was the most affected bacterial strain in our study, followed by Salmonella Enteritidis and E. coli O157:H7. Since L. monocytogenes and Salmonella Enteritidis were the most affected strains in lower $\mathrm{pH}$ regarding both MIC of CA and OEO, individual sensitivity of these strains to acidic conditions can play a role.

The results of this study demonstrate the effectiveness of oregano essential oil in combination with caprylic acid against foodborne pathogens in vitro. Further research is needed to evaluate the effectiveness in food substrates and the sensory acceptability of the effective mixture.

\section{Acknowledgement}

This study was funded by grant No. MSM 6215712402 provided by the Ministry of Education, Youth and Sports of the Czech Republic.

\section{References}

Boyen F, Haesebrouck F, Vanparys A, Volf J, Mahu M, Van Immerseel F, Rychlik I, Dewulf J, Ducatelle R, Pasmans F 2008: Coated fatty acids alter virulence properties of Salmonella Typhimurium and decrease intestinal colonization of pigs. Vet Microbiol 132: 319-327

Burt S 2004: Essential oils: their antibacterial properties and potential applications in foods - a review. Int J Food Microbiol 94: 223-253

Desbois AP, Smith VJ 2010: Antibacterial free fatty acids: activities, mechanisms of action and biotechnological potential. Appl Microbiol Biotechnol 85: 1629-1642

Dimitrijevic SI, Mihajlovski KR, Antonovic DG, Milanovic-Stevanovic MR, Mijin DZ 2007: A study of the synergistic antilisterial effects of a sub-lethal dose of lactic acid and essential oils from Thymus vulgaris L., Rosmarinus officinalis L. and Origanum vulgare L. Food Chem 104: 774-782

Di Pasqua R, De Feo V, Villani F, Mauriello G 2005: In vitro antimicrobial activity of essential oils from Mediterranean Apiaceae, Verbenaceae and Lamiaceae against foodborne pathogens and spoilage bacteria. Ann Microbiol 55: 139-143

Friedman M, Henika PR, Mandrell RE 2002: Bactericidal activities of plant essential oils and some of their isolated constituents against Campylobacter jejuni, Escherichia coli, Listeria monocytogenes, and Salmonella enterica. J Food Protect 65: 1545-1560

Gutierrez J, Barry-Ryan C, Bourke P 2009: Antimicrobial activity of plant essential oils using food model media: Efficacy, synergistic potential and interactions with food components. Food Microbiol 26: 142-150

Jensen RG, Ferris AM, Lammi-Keefe CJ, Henderson RA 1990: Lipids of bovine and human milks: a comparison. J Dairy Sci 73: 223-240

Juven BJ, Kanner J, Schved F, Weisslowicz H 1994: Factors that interact with the antibacterial action of thyme essential oil and its active constituents. J Appl Bacteriol 76: 626- 631

Kinderlerer JL, Lund BM 1992: Inhibition of Listeria monocytogenes and Listeria innocua by hexanoic and octanoic acids. Lett Appl Microbiol 14: 271-274

Nevas M, Korhonen AR, Lindström M, Turkki P, Korkeala H 2004: Antibacterial efficiency of Finnish spice essential oils against pathogenic and spoilage bacteria. J Food Protect 67: 199-202

Nobmann P, Smith A, Dunne J, Henehan G, Bourke P 2009: The antimicrobial efficacy and structure activity of relationship of novel carbohydrate fatty acid derivates against Listeria spp. and food spoilage microorganisms. Int J Food Microbiol 128: 440-445

de Oliveira CEV, Stamford TLM, Neto NJG, de Souza EL 2010: Inhibition of Staphylococcus aureus in broth and meat broth using synergies of phenolics and organic acids. Int J Food Microbiol 137: 312-316 
Penalver P, Huerta B, Borge C, Astorga R, Romero R, Perea A 2005: Antimicrobial activity of five essential oils against origin strains of the Enterobacteriaceae family. APMIS 113: 1-6

Ricke SC 2003: Perspectives on the use of organic acids and short chain fatty acids as antimicrobials. Poultry Sci 82: 632-639

Skřivanová E, Marounek M, Benda V, Březina P 2006: Susceptibility of Escherichia coli, Salmonella sp. and Clostridium perfringens to organic acids and monolaurin. Vet Med-Czech 51: 81-88

de Souza EL, de Barros JC, da Conceicao ML, Neto NJG, da Costa ACV 2009: Combined application of Origanum vulgare L. essential oil and acetic acid for controlling the growth of Staphylococcus aureus in foods. Braz J Microbiol 40: 387-393

Zhou F, Ji BP, Zhang H, Jiang H, Yang ZW, Li JJ, Li JH, Ren YL, Yan WJ 2007: Synergistic effect of thymol and carvacrol combined with chelators and organic acids against Salmonella Typhimurium. J Food Protect 70: 1704-1709 